\title{
THE FUNCTION OF SWEARING IN DONALD TRUMP'S UTTERANCES DURING PRESIDENTIAL DEBATE IN 2016
}

\author{
*Dedek Mahiroh \\ **Dra. Meisuri, M.A \\ ** Drs.Lidiman Sahat Martua Sinaga, M.Hum
}

\begin{abstract}
The study deals with the function of swearing in Donaldtrump'sutterances during the presidentialdebate. In this study, the researcher focuses onthe typesand the functionsof swearing inDonald Trump's utterances during the presidential debate.The research used the descriptive qualitative method.The data were taken from video's transcript ofAmerica presidential debate in 2016. There were three video's transcript used as the sample, they were first presidential debate broadcasted on September $26^{\text {th }}$ 2016, second presidential debate broadcasted on October $9^{\text {th, }} 2016$ and third presidential debate broadcasted on October 19 ${ }^{\text {th, }}$ 2016. Based on the analysis of data, the findings said that there were five types of swearing in Donald Trump's utterances during a presidential debate in 2016 namely politic term, religious matter, death term, animal term, and sex or copulative term.However, there were three functions of swearing in Donald trump's utterances during a presidential debate in 2016 namely descriptive swearing, abusive swearing, and idiomatic swearing.
\end{abstract}

Keywords:Swearing, Taboo words, Sociological Approach, US presidential debate in 2016, Donald Trump 


\section{INTRODUCTION}

Languageplays a huge role in humans' life, particularly in the area of social interaction. There are many ways of using language that people can use to express their feelings. Besides using the politeness strategies, people also use the impoliteness strategies and one of them is by producing swearwords.

Swearword is a word or combination of some words that produces swear meaning that is usually used by someone when he or she is angry. (Nasution and Rosa, 2012:2)

Swearing has always been regarded as an undereducated, obscene, rude and profanelanguage in society. Swearing is regarded to reflect bad behavior, lack of education and linguistic poverty. As a public figure, a politician has to pay attention to his behavior by being polite.

However, some politicians such as Vice president Joe Biden, Senator John Kerry, George W. Bush who have a good educational background often use informality including swearing in political language. This phenomenon occurs all around the world. Not only in America, butalso in Indonesia, where the Governor of Jakarta namely Ahok often broke the principle of politeness by using assertive language.

Lately, Donald Trump has earned his place as one of the most controversial politicians. He swears a lot. He has also made many controversial quotes throughout his presidential campaign. He is a racist, particularly by cursing a specific group which often belongs to the minority. 
He usually directs his controversial comments for Muslims, illegal immigrants, and other people.

Many people predict Trump will not be elected. Pro and contra about his politic are coloring his political campaign in USA presidential election in 2016. Trump collapsed many politician experts prediction about him. Some of them are Richard Gutsy a democratic politician, he predicted that Trump would not be elected as the nominee of Republican Party. The 44th USA President Barack Obama quoted that Trump can not be the President of United States of America. Being a President is a really serious job and this is not a reality show, Trump's politic is not serious politic. Ted Cruz quoted that if Trump becomes the nominee of Republican and becomes US President, it will be a disaster for Republican Party and American government. (Khurniawan,2017:5)

In a context like political campaign debates where politicians compete for a determinate political office, and continuously attempt to damage and dominate the counter candidate as a result, it would be unimaginable to conceive of impoliteness towards the rival differently from intended impoliteness in terms of aggravation or attack against his/her persona.(Bousfield and Locher, 2008: 104).

Culpeper (1996:357) support his idea with saying Impoliteness strategies challenging the idea that the speaker does not always want to protect the face of the recipient but wants to attack the face. It must be stressed that 
the list of the impoliteness strategyis not exhaustive and that the strategies depend upon an appropriate context to be impolite.

Swearing has two opposite effects, it can be positive or negative. Cavazza and Guidetti (2014:544) found that informality in political language makes the audience feel close to that politician because vulgarity is widespread and particularly associated with friendly conversation and context. The use of swearing makes the politicians sound less formal which may make people feel close to the politicians and thus perceive them in a more positive way. Wang (2013:71) support their idea with saying swearing have a positive function such as to express emotions, verbal emphasis, and group solidarity.

However, Vingerhoets (2013:1) having a different opinion with saying people who swear are often judged negatively because the uttered swearing can shock and disturb others.

Based on the explanation above, this study tries to find out the function of swearing in Donald Trump's presidential debate in 2016.

\section{THE PROBLEMS OF STUDY}

Based on the background of study, this study formulated the problem as the following:

1. What types of swearing were found in Donald Trump'sutterances in his presidential debate?

2. What were the functions of swearing uttered by Donald Trump? 


\section{REVIEW OF LITERATURE}

The study was completed with theories correlated to the topic in order to enhance the knowledge toward the topic. The theories were consisted of definition of swearing,types of swearing and function of swearing.

Swearword comes from word of swear. The meaning of "swear" is to make astrong promise to someone or to promise to do something. In general,swearword has two meanings. The first is to promise or to swear to keep a secret,and the second is to describe rude word or curse. Swearing in this study defined as using offensive language, say a bad or curse word (Nasution and Rosa, 2012:2)

\section{Types of swearwords by Wardhaugh (2006) and Liedlich (1973)}

a) Sex or Copulative Term

The term "copulative" come from the word "couple", which means a combination of two people (man and woman) united by marriage, and also having united in sexual intercourse. This term becomes "copulae" which means something that connects or joins together and then it becomes "copulative" which means things related to sexual intercourse between man and woman. The example of this category is fuck. (Rahayu, 2014:22)

b) Death Terms

The term "death" means saying something about death without euphemism or empathy. In addition, say something about death scarily or disgustingly also prohibited. 


\section{c) Excretion Terms}

The term "excretion" comes from "excrete" which means to separate and eliminate the solid waste matter or the bowels of our body through the anus. The word related to this term is shit. (Rahayu, 2014:22)

d) Bodily Function Term

The term means that the sex organs of human beings for the production system for the next generation. The words, which belong to sex organs of being, are for instance "cock, rooster, haystack, haycock" (Liedlich 1973:108). Another example of this term is the word "ass".

e) Religious matters

The religious matter that used in religious context is fine to use. However, some people find their use outside formal circumstance as offensive or shocking.

f) Animal Term

This term is related to the animal, the behavior of animals, religious beliefs and practices from prehistoric times.Usually, people using the animal term in swearing to the insulting of others.

g) Politic term

Swearing in "politic" term means insulting or saying bad words to a person or a group that related to their nationality, government, social, culture, race or ethnicity. When someone insults a country or government, it causes anger and conflict within a group. 


\section{Function of Swearing}

One of the earliest scientific explanations of pragmatic function of swearing was provided by Steven Pinker. Pinker (2007:251), breaks possible function of swearing into five categories:

a) Descriptive swearing: theexact opposite of euphemism. Forces listener to think about the negative or provocative matter. Using the wrong euphemism has a dysphemistic effect. (Example: He fucks her!)

b) Abusive swearing: for abuse or intimidation or insulting of others (Example: You motherfucking son of a bitch! Fuck you asshole)

c) Idiomatic swearing: swearing without really referring to the matter just using the words to arouse interest, to show off, and express to peers that the setting is informal. (Example: Fuck, man.)

d) Emphatic swearing: to emphasize something with swearing. (Example: It was so fucking big!)

e) Cathartic swearing: when something bad happens like coffee spilling, people curse. One evolutionary theory asserts it is meant to tell the audience that you're undergoing a negative emotion. (Example: Aww, fuck!, Damn this coffee).

f)

\section{RESEARCH METHODOLOGY}

Methodology

This research used the descriptive qualitativemethod togenerate findings to reliable, valid and better comprehension. 
The data were taken from video's transcript ofAmerica presidential debate in 2016. There were 3 video's transcript used as the sample, they were first presidential debate broadcasted on September $26^{\text {th }}$ 2016, second presidential debate broadcasted on October $9^{\text {th, }} 2016$ and third presidential debate broadcasted on October $19^{\text {th, }}$ 2016. The data source of this research was the video of America presidential debate in 2016 by downloading on www.youtube.com.

In order to collect thedata, this study used some steps. First, the researcher watched the video be downloaded on www.youtube.com. Second, the researcher made video's transcript of America presidential debate 2016. The last, the researcher read the transcription for several times until the researcher understood what the videos were talking about.

Then, the data was analyzed by using descriptive qualitative method in which the steps that were done, theywere; identifying, classifying, explaining, calculating the percentage, finding the most dominant and making the conclusion from the analysis that had been conducted.

\section{DATA ANALYSIS AND RESEARCH FINDINGS}

\section{Data Analysis}

After collecting and analyzing the data, it was found that there were fifteen swearing, five types of swearing and three functions of swearing in Donald Trump utterances during a presidential debate in 2016. The types of swearing that were found were those that defined as a politic term, religious matter, death term, animal term, and sex or copulative term. The functions of swearing that were 
found were those that defined as descriptive swearing, abusive swearing, and idiomatic swearing.

\section{The types of swearing found in Donald Trump's utterances in presidential debate in 2016}

\section{a. Sex or Copulative term}

"Copulative" comes from the word couple which means that combination of two people with different gender who are married, and also has committed to sexual contact. This term becomes copulative which means something that connects at once and involves man and woman. (Liedlich, 1973:108).

Donald Trump called Hillary Clinton "a nasty woman" in the third presidential debate in 2016. Here is the dialogue:

Clinton: "Well, Chris, I am recorded as saying we need to put more money into Social Security Trust fund. That's part of my commitment to..."

Trump: "Such a nasty woman".

The word "nasty woman" above categorize as sex or copulative term because the word "nasty woman" has the same meaning with the word "bitch".This word very rude and vulgar.

\section{b. Death Term}

There are two states where Donald trump swearing using Death term. These statements were found in second and third presidential debate in 2016. Here are the dialogues: 
Trump: “...You know, when we have aworld where you have ISIS

chopping off heads, where you havethem, frankly, drowning

people in steel cages..."

Trump: "...If you go with what Hillary is saying, inthe ninth month you cantake the baby and rip the baby out of thewomb of the mother just prior to the birth of the baby."

The sentences "chopping off heads" and "take the baby out of the womb of the mother" are scare rhetoric. These sentences are scare and disgusting. As a publicfigure, it is better if Donald trump using another word to say what he meant.

\section{c. Religious matter}

There are four states where Donald trump swearing using religious matter term. These statements were found in first, second and third presidential debate in 2016.For example:

Trump: "I think we have to get NATO to go into the Middle East with us. In addition to surrounding nations, and we have to knock the hell out of ISIS. And we have to it fast."

Trump: "I was so surprised to see him sign on with the devil."

A religious matter like the word "hell" that used in religious context are fine to use.However, some people find their use outside formal circumstance as offensive or shocking. Furthermore, insult someone by saying he or she is devil is also prohibited.

\section{d. Animal Term}

This term is related to the animal, the behavior of animals, religious beliefs and practices from prehistoric times.People using the animal term in swearing to 
the insulting of others.Here is the dialogue when Donald trump swearing using animal term refer to Hillary in a third presidential debate in 2016:

Trump: “...We're in very serioustrouble. Because we have a country with tremendous numbers ofnuclear warheads, 1,800, by the way. Where they expanded and wedidn't. 1,800 nuclear warheads. And she is playing chicken, Look."

\section{e. Politic term}

Swearing in "politic" term means insulting or saying bad words to a person or a group that related to their nationality, government, social, culture, race or ethnicity. When someone insults a country or government, it causes anger and conflict within a group.

Here are the dialogues of swearing in politic term found in Donald Trump's utterances:

Trump: "When I look at the Iran deal and how bad a deal it is for us, it's a one-sided transaction, where we're giving back $\$ 150$ billion to a terrorist state, really the number one terrorist state."

Trump: "Nobody can believe how stupid our leadership is."

The politic term is the most dominant types of swearing found in Donald Trump utterances in video's transcript ofAmerica presidential debate in 2016. In this video, Donald Trump swearing not only refers to other country but also refer to government, immigrant, and media. 


\section{The functions of swearing found in Donald Trump utterances in presidential debates in 2016}

\section{a. Descriptive Swearing}

Descriptive swearing is the swearing that exact opposite of euphemism. This swearing forces listener to think about the negative or provocative matter. Using the wrong euphemism has a dysphemistic effect. For example:

\section{Trump: "You know, when we have a world where you have ISIS chopping off heads, where you have them, frankly, drowning people in steel cages...." \\ Trump: "In the ninth month you can take baby and rip the baby out of the womb of the mother just prior to the birth of the baby."}

The dialogue above force listener to imagine scare things such as people who chopping off heads and drowning people in steel cages.It forces the listener to imagine that scare words.

\section{b. Abusive swearing}

Abusive swearing is the swearing for abuse or intimidation or insulting of others. Here are some of the abusive swearing found in Donald Trump utterances during presidential debate 2016:

Trump: "Such a nasty woman." (refers to HillaryClinton)

Trump: "I was so surprised to see him sign on with the devil." (refers to HillaryClinton)

Abusive swearing is the most dominant function of swearing found in Donald Trump utterances during a presidential debate in 2016. Most of his swearing used for insulting HillaryClinton. He said that Hillary Clinton is a nasty 
woman, devil, puppet, etc.However, he used abusive swearing not only for insulting HillaryClinton as his rival in the presidential campaign but he also insulting another country. He said Iran is a terrorist state.

\section{c. Idiomatic Swearing}

Idiomatic Swearing is swearing without really referring to the matter just using the words to arouse interest, to show off, and express to peers that the setting is informal. For example:

Trump: "I will knock the hell out of ISIS."

Trump: "Why the hell didn't you do it over the last 15, 20 years? You were very much involved."

Donald Trump add the word "hell" in some states to make it become informal. He was not really referring to the matter.

\section{CONCLUSION AND SUGGESTIONS}

\section{Conclusions}

After analyzed the functions of swearing in Donald Trump's utterances during a presidential debate in 2016, the conclusion was finally formed as followed:

1. There were five types of swearing that were found in Donald Trump's utterances during a presidential debate in 2016 were those that defined as a politic term, religious matter, death term, animal term, and sex or copulative term. 
2. There were three functions of swearing were found in Donald trump's utterances during a presidential debate in 2016. They were descriptive swearing, abusive swearing, and idiomatic swearing.

\section{Suggestions}

Considering the conclusion that has been formed above, several suggestions regarding the topic of this study was served and listed as followed:

1. This study was expected could be the reference to give a contribution for further study which criticized impoliteness in political language. Impoliteness that were found in this topic shown that the failed rules in the language of politics.

2. This study was expected to be able to complete the space of unfilled findings regarding this study topic. 


\section{REFERENCES}

Bousfield, D. and Locher, A. 2008. Impoliteness in Language:Studies on its Interplay with Power in Theory and Practice. Berlin: Walter de Gruyter GmbH

Cavazza, N, and Guidetti, M. 2014.Swearing in Political Discourse: Why Vulgarity Works. Unpublished Journal. Bologna: University of Modena

Cresswell, J.W. 2013. Research Design Qualitative, Quantive and Mixed Methods Approach. Newyork: University of Nebraska

Culpeper, J. 1996.Towards an Anatomy of Impoliteness. Unpublished Journal. Lancaster: Lancaster University

Hughes, G. 2006. An Encyclopedia of Swearing: The social history of oaths, profanity, foul language, and ethnic slurs in the English speakingworld. Newyork: M.E.Sharpe

Khurniawan, R. 2017. The Impoliteness Strategies In Republican Party's Debate Of Donald Trump. Surakarta:MuhammadiyahUniversity Of Surakarta

Liedlich, R. 1973. Coming to terms with language: an anthology, London: John Wiley\&Sons

Nasution, R.F., and Rosa, R, N. 2012. Swearwords Found in Chat Room Yahoo Messenger. Unpublished Thesis. Padang: State University of Padang 
Pinker, S. 2007. The Stuff of Thought. Newyork:Penguin GroupViking Press

Rahayu, W. 2014.An Analysis Of Swear Words Used By The Characters In The Grey Movie.Unpublished Thesis. Surabaya: State Islamic UniversitySunan Ampel Surabaya

Vingerhoets, A.J.J.M. 2013. Swearing: A Biopsychosocial Perspective. Oxford: Oxford University Press.

Wang, N. 2013.An analysis of the pragmatic functions of "swearing" in interpersonal talk.Griffith Working Papers

Wardhaugh, R. 2006. An Introduction to Sociolinguistics. Oxford: Blackwell Publishing 